\title{
Effects of Mindfulness-Based Stress Reduction (MBSR) on Stress, Heart Rate Variability, Affect, and Wellbeing among People with Schizophrenia
}

\author{
Ae Sil Kim ${ }^{1}$, Mi Heui Jang ${ }^{2, *(D)}$ and Min Jung Sun ${ }^{2}$ (D) \\ 1 Department of Nursing, Yeungnam University College, Daegu 42415, Korea; interkim2@hanmail.net \\ 2 College of Nursing Science, Kyung Hee University, Seoul 02447, Korea; dnfntk0213@khu.ac.kr \\ * Correspondence: mhjang@khu.ac.kr; Tel.: +82-2-961-0592
}

check for

updates

Citation: Kim, A.S.; Jang, M.H.; Sun, M.J. Effects of Mindfulness-Based Stress Reduction (MBSR) on Stress, Heart Rate Variability, Affect, and Wellbeing among People with Schizophrenia. Int. J. Environ. Res. Public Health 2021, 18, 11871. https://doi.org/10.3390/ijerph 182211871

Academic Editor: Alexandra Fiocco

Received: 24 August 2021

Accepted: 9 November 2021

Published: 12 November 2021

Publisher's Note: MDPI stays neutral with regard to jurisdictional claims in published maps and institutional affiliations.

Copyright: (C) 2021 by the authors Licensee MDPI, Basel, Switzerland. This article is an open access article distributed under the terms and conditions of the Creative Commons Attribution (CC BY) license (https:/ / creativecommons.org/licenses/by/ $4.0 /)$

\begin{abstract}
Mindfulness-based stress reduction programs have been found to be effective in reducing the stress response and improving the psychological wellbeing of various populations. We aimed to confirm the effects of a mindfulness-based stress reduction program on perceived stress, heart rate variability, positive and negative affect, and subjective wellbeing of community-dwelling people with schizophrenia. The participants in this study were 26 people with schizophrenia (experimental group: 14, control group: 12) enrolled in two community mental health centers located in Gyeonggi Province in South Korea. In the experimental group, the mindfulness-based stress reduction program was applied once a week for 60 min over 8 weeks. The experimental group showed a significantly greater decrease in perceived stress and negative affect, as well as significantly greater improvement in heart rate variability than the control group. The mindfulness-based stress reduction program was an effective nursing intervention to reduce stress and negative affect in people with schizophrenia.
\end{abstract}

Keywords: schizophrenia; stress; mindfulness; affect

\section{Introduction}

The international lifetime prevalence of schizophrenia among noninstitutionalized persons is $0.3 \%$ to $0.7 \%$ [1]. Schizophrenia is a disease with a high socioeconomic burden due to functional deterioration and chronic progression, to the point that it comprises $20 \%$ of all mental health-related direct costs and belongs to the top 10 diseases with the highest disability rate [2]. People with schizophrenia are vulnerable to stress due to difficulties in interpersonal relationships and low self-esteem [3]. For this reason, there is a vicious cycle of being discharged from the hospital and then subjected to rehospitalization due to relapse induced by vulnerability to stress and environmental stressors, resulting in numerous difficulties in returning to society and adapting thereto $[4,5]$.

The personal and internal stress factors experienced by people with schizophrenia in the community include side-effects caused by antipsychotic drugs, other health problems [6], psychotic symptoms such as hallucinations and delusions of persecution, and reduced quality of life and wellbeing due to frequent cycles of hospitalization and discharge [7]. Furthermore, people with schizophrenia experience discrimination in their daily life, as well as a high level of stress from social prejudice and stigma [8]. Psychosocial rehabilitation therapy and drug therapy have been provided to people with schizophrenia to reduce their stress, control symptoms, and restore function [9]. The various approaches to psychosocial interventions that have been developed to date provide significant benefits in improving patients' symptoms, drug compliance, and relapse [10]. However, most current approaches to psychosocial interventions pay relatively little attention to patients' acceptance of schizophrenia and their incomprehensible and stressful experiences of psychotic symptoms. Many of them also involve limited strategies to empower self-management of the illness [10]. 
Recent studies have revealed that mindfulness-based interventions (MBIs) are effective in the treatment of various mental health disorders, and they may improve psychological symptoms and reduce stress in persons with a mental illness [11,12]. Moreover, studies have shown that MBIs are effective at reducing cardiovascular disease, depression [13,14], anxiety [15], and stress [16,17], as well as improving mindfulness, positive affect, negative affect, emotion regulation, wellbeing [18], and quality of life [19]. Mindfulness can be understood as a specific form of meditation that seeks to augment various psychological functions by means of a synergic effort between attention regulation, self-awareness, and emotion regulation, thereby increasing psychological resilience and self-regulation [20]. As an example of an MBI, mindfulness-based stress reduction (MBSR) programs were developed in a behavioral medicine setting for populations with a wide range of chronic pain and stress-related disorders [21]. Scientific evidence has demonstrated that MBSR programs can have a profound benefit via the mind-body connection; specifically, the practice of mindfulness results in an increase of awareness, as individuals purposefully pay attention to the present moment and nonjudgmentally monitor the unfolding of experiences moment by moment $[22,23]$.

Recent systematic reviews and meta-analyses of randomized controlled trials have found that MBIs reduced psychotic symptoms, positive symptoms, negative symptoms, depressive symptoms, and duration of rehospitalization among people with schizophrenia, as well as improving their level of function and awareness of illness [24,25]. In the last few decades, MBIs have rapidly become more popular, and extensive research has explored their efficacy as treatments for various psychological disorders [26]. However, there is limited evidence regarding whether MBIs are applicable for schizophrenia in South Korea. One of the reasons for the scarcity of evidence is that meditation in MBIs was previously considered inappropriate for people with schizophrenia since it might influence their psychotic symptoms [27]. However, in South Korea, studies with conflicting results have been reported. On one hand, a study argued that MBIs are inappropriate for people with schizophrenia because meditation could affect their psychotic symptoms [27]. On the other hand, studies $[28,29]$ have shown that MBIs have a positive effect on depression, emotion, and responses to stress in people with schizophrenia. In light of these discrepancies in the literature, there is a need for an evidence-based study of an MBSR program focusing on stress alleviation with confirmation of the intervention's effects using objective measures, including physiological indices related to the stress response.

Thus, considering previous studies, this study aimed to apply an MBSR program to people with schizophrenia residing in the local community and to verify its effects. It was hypothesized that engaging in the MBSR program would improve indices of wellbeing and affect, as well as improve stress reactivity among outpatients with chronic schizophrenia. Specifically, the aim of this study was to confirm the effects of the MBSR program on perceived stress, heart rate variability (HRV), positive and negative affect, and subjective wellbeing of community-dwelling people with schizophrenia. The study hypotheses were as follows:

Hypothesis 1 (H1). Compared to the control group, the MBSR group will display a greater decrease in perceived stress.

Hypothesis 2 (H2). Compared to the control group, the MBSR group will display a greater increase in heart rate variability.

Hypothesis 3 (H3). Compared to the control group, the MBSR group will display a greater increase in positive affect. 
Hypothesis 4 (H4). Compared to the control group, the MBSR group will display a greater decrease in negative affect.

Hypothesis 5 (H5). Compared to the control group, the MBSR group will display a greater increase in subjective wellbeing.

\section{Materials and Methods}

\subsection{Study Design and Participants}

The current study employed a quasi-experimental, nonrandomized design. The participants of this study were residents in Cities N and U, Gyeonggi Province, South Korea, who were registered members of community mental health centers. The specific selection criteria for the participants were as follows: (1) having been diagnosed with schizophrenia by a psychiatrist, (2) having insight into their condition based on a score of 9 or less according to the Scale to Assess Unawareness of Mental Disorder (SUMD) [30], (3) having symptoms of moderate severity as shown by a score of less than 41 on the Brief Psychiatric Rating Scale (BPRS), (4) being between 19 and 64 years of age and not having changed their regimen of major psychotropic drugs that may affect physiological indicators during the study period, (5) not having taken part in a program similar to this study within the last 6 months, and (6) understanding the objectives of this study and agreeing to participate in this study in written form. The exclusion criteria were (1) having difficulty in verbal and non-verbal communication, (2) having been assessed with an absence of insight based on a score of 10 or more according to the SUMD, (3) having severe psychiatric symptoms as shown by a score of 41 or more on the BPRS, (4) having major changes in their regimen of psychiatric drugs during this program, and (5) having been diagnosed with personality disorders or substance-related and addiction disorders.

Power analysis ( $\mathrm{G}^{*}$ Power [31]) for a medium effect size ( $f 2=0.25[32], \alpha=0.05, \mathrm{~B}=0.8$ ) using a repeated-measures within-between interaction, with two groups, three points of measurement, and a correlation of 0.50 between repeated measures, indicated a minimum sample size of 28 participants. Considering a dropout rate of $20 \%$ based on a previous study [33], a total of 36 participants were recruited (18 participants with schizophrenia each for the experimental and control groups) among participants who expressed their intention to participate in the program and met the selection criteria (Figure 1). In the experimental group, two participants refused to further participate in this program after the first session, one participant participated in the program, but refused to fill out the questionnaire, and one participant moved to another place. In the control group, two participants discontinued participation for personal reasons, one participant refused to undergo HRV testing, two participants could not be reached afterward, and one participant discontinued participation for employment. The final sample size included a total of 26 participants, 14 in the experimental group and 12 in the control group. 


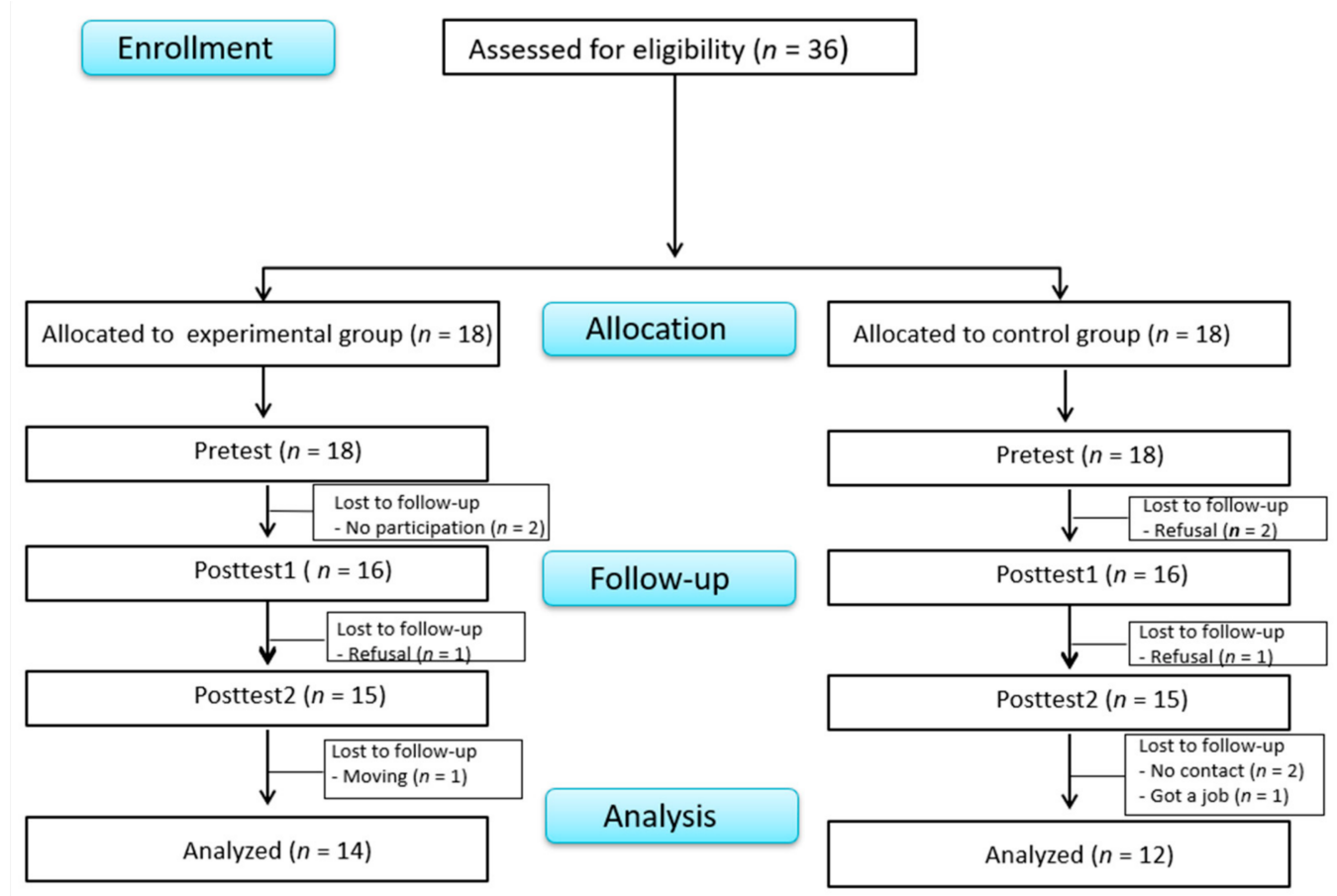

Figure 1. Flowchart of participants.

\subsection{MBSR Program}

The MBSR program applied in this study was based on the principles articulated by Kabat-Zinn [23], and the researchers constructed the timing and content of the program to maintain the therapeutic environment of people with schizophrenia who visited the community mental health center. The MBSR program used in this study consisted of a total of eight sessions. To confirm its applicability to people with schizophrenia, the content and methods of the program were constructed with input from a professor of mind and body healing, who is an international expert in MBSR programs, and another professor of psychiatric and mental health nursing, who is a certified psychiatric mental health nurse. The principal investigator (PI) in this study is a certified psychiatric mental health nurse who has completed MBSR advanced training. The PI received MBSR training from an MBSR program expert who is the only certified leader in South Korea and who is recognized by the MBSR Headquarters (CFM: Center for Mindfulness) at the University of Massachusetts Medical School, USA. Furthermore, the PI's doctoral dissertation was a study on an MBSR program for people with schizophrenia, and the PI currently educates university students about that program.

The theoretical rationale for the effect of the MBSR program, investigated in this study, is the self-regulation model according to which physical and mental health improves through mindfulness interventions $[34,35]$. According to this theory, the program was constructed in order to reduce stress in people with schizophrenia.

For the experimental group, the date and time of the program were decided in consideration of the schedule of the weekly rehabilitation program of the community mental health center through consultations with the center's professionals. The content of each session of the program was as follows: session 1, orientation to the MBSR program and recognition of internal resources; session 2, perception and creative responding: a way to see and respond; session 3, pleasure and power in being present; session 4, how does conditioning and perception shape our experience; session 5, awareness of conditioned patterns of escape from difficulty and making selective reactions; session 6 , awareness and balancing in stressful situations, especially acute or chronic stress; session 7, integrating mindfulness practice; session 8 , keeping up mindfulness meditation in daily life and finishing the program. Participants were instructed to practice the meditation techniques that 
they had learned each week in the program regularly at home, to record notes on their practice in the provided booklet, and to share them with other participants when attending the following week's session. The first author directed the program, and one social worker and one psychiatric nurse helped to implement the MBSR program. Following an MBSR program for people with an anxiety disorder [36], the program was carried out for eight weeks, with one session per week and $60 \mathrm{~min}$ per session (Table 1).

Table 1. Mindfulness-based stress reduction program of the study.

\begin{tabular}{|c|c|c|c|}
\hline Session & Themes & Content of the Program & Time (min) \\
\hline \multirow{3}{*}{1} & Orientation to the MBSR & 1. MBSR program introduction & 20 \\
\hline & program and recognition of & 2. Mindful breathing and body scan meditation & 25 \\
\hline & internal resources & 3. Review and discussion & 15 \\
\hline \multirow{3}{*}{2} & Perception and creative & 1. Mindful breathing and body scan meditation & 20 \\
\hline & responding: a way to see & 2. Mindful eating meditation & 20 \\
\hline & and respond & 3. Review and discussion & 20 \\
\hline \multirow{3}{*}{3} & \multirow{3}{*}{$\begin{array}{l}\text { Pleasure and power in } \\
\text { being present }\end{array}$} & 1. Mindful breathing meditation & 20 \\
\hline & & 2. Mindful hatha yoga meditation & 25 \\
\hline & & 3. Meditation discussion & 15 \\
\hline \multirow{3}{*}{4} & \multirow{3}{*}{$\begin{array}{l}\text { How does conditioning and } \\
\text { perception shape our experience }\end{array}$} & 1. Mindful breathing and sound meditation & 10 \\
\hline & & 2. Mindful walking meditation & 30 \\
\hline & & 3. Review and discussion & 20 \\
\hline \multirow{3}{*}{5} & \multirow{3}{*}{$\begin{array}{l}\text { Awareness of conditioned } \\
\text { patterns of escape from } \\
\text { difficulty and making } \\
\text { selective reactions }\end{array}$} & 1. Mindful breathing and mindful sound meditation & 20 \\
\hline & & $\begin{array}{l}\text { 2. Mindful thoughts and emotions meditation: review } \\
\text { and discussion }\end{array}$ & 20 \\
\hline & & $\begin{array}{l}\text { 3. Explanation of stress response and mindfulness } \\
\text { autonomic response }\end{array}$ & 20 \\
\hline \multirow{3}{*}{6} & \multirow{3}{*}{$\begin{array}{l}\text { Awareness and balancing in } \\
\text { stressful situations, especially } \\
\text { acute or chronic stress }\end{array}$} & $\begin{array}{l}\text { 1. Mindful breathing meditation and mindful } \\
\text { sound meditation }\end{array}$ & 20 \\
\hline & & 2. Mindful thoughts and emotions meditation & 20 \\
\hline & & 3. Review and discussion & 20 \\
\hline \multirow{3}{*}{7} & \multirow{3}{*}{$\begin{array}{l}\text { Integrating mindfulness } \\
\text { practice }\end{array}$} & 1. Mindful breathing and body scan meditation & 20 \\
\hline & & 2. Review and discussion & 20 \\
\hline & & 3. Generosity in interpersonal relationships & 20 \\
\hline \multirow{3}{*}{8} & Keeping up mindfulness & 1. Mindful breathing meditation & 25 \\
\hline & meditation in daily life and & 2. Review and stress reduction discussion & 25 \\
\hline & finishing the program & 3. Explain home practice and finishing meditation & 10 \\
\hline
\end{tabular}

\subsection{Measures}

\subsubsection{Perceived Stress}

Perceived stress was measured using a tool translated into Korean by Park and Seo [37] according to the Perceived Stress Scale (PSS) developed by Cohen [38]. This tool measures the extent to which an individual perceives their life over a month as unpredictable, uncontrollable, and excessively stressful. The tool has a total of 10 items on a five-point Likert scale from 0 ("strongly disagree") to 4 ("strongly agree"). Items 4, 5, 7, and 8 are reverse-scored; thus, a higher average score corresponds to higher perceived stress. Regarding the internal consistency of the Korean version of the PSS, Cronbach's $\alpha$ was 0.77 for negative perceptions and 0.74 for positive perceptions. This tool showed a good fit for measuring validity, and the criterion validity was determined to be high [37]. Cronbach's $\alpha$ was 0.77 in this study.

\subsubsection{Heart Rate Variability (HRV)}

HRV was measured using uBioMacpa Pro (BioSense Creative Co., Ltd., Seoul, Korea), which is a professional-grade HRV measurement instrument. Before starting the test in a quiet room, a participant sat in a chair for $5 \mathrm{~min}$ or more to reach calmness. Subsequently, a sensor measuring blood flow was attached to the skin surface of the index finger. This study measured short-term HRV for $2.5 \mathrm{~min}$. A sensor was attached to the left index finger 
to measure the standard deviation of the normal-to-normal interval (SDNN). The SDNN is an antistress indicator. A SDNN value of 30 or more is considered to be normal, while lower values of the SDNN imply that an individual's ability to adapt to stress is low and, simultaneously, that the degree of stress is high.

\subsubsection{The Positive and Negative Affect Schedule (PANAS)}

Affect was measured using the Korean version of the Positive and Negative Affect Schedule (K-PANAS) by Lim [39], which is a translation and standardization of the Positive and Negative Affect Schedule (PANAS) developed by Watson et al. [40]. This tool has a total of 20 items on a five-point Likert scale from 1 ("not at all") to 5 ("extremely"), consisting of 10 items regarding positive affect and 10 items regarding negative affect. Each score for positive and negative affect ranged from 10 to 50, with the higher scores indicating a higher level of affect. Regarding the reliability of this tool at the time of development in the research of Watson et al. [40], Cronbach's $\alpha$ was 0.88 for positive affect and 0.85 for negative affect. Regarding the internal reliability of the K-PANAS [39] for mentally ill patients, Cronbach's $\alpha$ was 0.87 for positive affect and 0.91 for negative affect. This tool showed favorable results for validity, and the criterion validity of this tool was high [39]. In this study, Cronbach's $\alpha$ was 0.72 for positive affect and 0.70 for negative affect.

\subsubsection{Subjective Wellbeing}

The subjective wellbeing of people with schizophrenia was measured using the Korean version of the Subjective Wellbeing under Neuroleptic Treatment Scale, Short Form (KvSWN-K), which was translated into Korean and validated by Kim et al. [41], according to the Subjective Wellbeing under Neuroleptic Treatment Scale (SWN) for people with schizophrenia developed by Naber et al. [42]. The KvSWN-K tool consists of five subfactors (emotional regulation, self-control, mental functioning, social integration, and physical functioning), and each subfactor consists of four items, totaling 20 items. This tool utilizes a six-point Likert scale from 1 ("not at all") to 6 ("extremely"), and the score ranges from 20 to 120 , with a higher score indicating higher subjective wellbeing. Ten items were reverse-scored. Regarding the internal reliability of this tool at the time of the development of KvSWN-K [41], Cronbach's $\alpha$ was 0.87. This tool showed favorable validity, as well as high concurrent validity with the EuroQoL-5D. Cronbach's alpha for each subscale ranged from 0.76 (social integration) to 0.88 (physical functioning) in the present study, and the overall Cronbach's alpha was 0.92 .

\subsection{Data Collection}

Before commencement of the study, the study objective and methods were explained to the directors of two community mental health centers located in G Province in South Korea, who provided permission and consent for program implementation. The data collection period was 11 December 2018 to 14 May 2019. To recruit participants, an information sheet on the MBSR program was distributed to people with schizophrenia in the community mental health centers. People with schizophrenia who were interested in participating in this program informed the psychiatric nurse who was in charge of the daytime rehabilitation program at the center. Regarding group allocation, two community mental health centers in Gyeonggi Province, which have similar service and treatment environments, were selected to prevent cross-contamination. All participants from one community mental health center were allocated to the experimental group and all participants from the other center were assigned to the control group. We selected participants with a similar distribution of gender, age, diagnosis, and symptoms in the two groups. After receiving consent from the center director, we met with patients who were eligible for participation at the center and explained the study objective and methods. Additionally, we promised to guarantee the anonymity and confidentiality of the collected data and to use the data for academic purposes only. Voluntary consent was then obtained verbally and in writing. 
The experimental group was divided into two teams, each of which contained nine participants, for effective team dynamics and progression of sessions for people with schizophrenia. The program was conducted on Tuesdays and Thursdays. To minimize measurement errors between examiners, a standardized protocol was implemented. To avoid the halo effect during data collection, two research assistants (not the principal researcher) conducted the assessment sessions. All participants were assessed at three time points: pre-test (1 week before program implementation), post-test (immediately after the experimental treatment ended), and the follow-up test (6 weeks after the experimental treatment ended). After completing data collection, a gift was offered to participants as compensation. In line with a previous study [43] applying an MBSR program, this study conducted a follow-up test after 6 weeks. In the pre-test, the study objective was explained to the participants by two research assistants. Subsequently, we assessed participants general characteristics and evaluated perceived stress, HRV, positive and negative affect, and subjective wellbeing. Both the post-test and follow-up test followed a similar procedure, although the assessment of general characteristics was excluded. After completing data collection, the control group was informed in advance that the MBSR program would be provided twice in the future. After completion of the study, all participants in the control group who expressed interest were provided with two sessions of 60 min each.

\subsection{Statistical Analysis}

All data were analyzed using SPSS Statistics 20.0 for Windows (IBM Corp., Armonk, NY, USA). The frequencies, percentages, means, and standard deviations were calculated for participants' general characteristics. Between-group differences were assessed using chi-square for categorical variables and independent $t$-tests for continuous variables (i.e., perceived stress, HRV, positive and negative affect, and subjective wellbeing). To analyze the effects of the MBSR program, a two-way repeated-measures ANOVA was used, with group as the between-group variable and assessment time as the within-group variable. Skewness and kurtosis tests were used to test the normality of the dependent variables. All variables were found to be normally distributed. Mauchly's test of sphericity was carried out; if it yielded significant results, we used Wilks' lambda for the multivariate tests, whereas, in the opposite case, we used the Greenhouse-Geisser test for univariate testing. Post hoc testing consisted of calculating changes in scores in the dependent variables from pre-testing, post-testing, and follow-up testing, followed by comparing these changes using the independent-sample $t$-tests.

\subsection{Ethical Considerations}

This study was approved by the Institutional Review Board (IRB) of K University (approval number: KHSIRB-18-041(NA)). All participants were informed about the content and purpose of this study and were provided a consent form to sign before the start of the study.

\section{Results}

\subsection{Baseline Characteristics and Between-Group Differences}

The experimental and control group were not statistically different according to the tested characteristic variables or baseline variables of interest (Table 2). 
Table 2. Baseline characteristics and between-group differences $(N=26)$.

\begin{tabular}{|c|c|c|c|c|c|}
\hline \multirow{2}{*}{ Characteristics } & \multirow{2}{*}{ Categories } & Exp. $(n=14)$ & Cont. $(n=12)$ & \multirow{2}{*}{$\chi^{2} / \mathrm{t}$} & \multirow{2}{*}{$p$} \\
\hline & & $n(\%) / \mathrm{M} \pm \mathrm{SD}$ & $n(\%) / \mathrm{M} \pm \mathrm{SD}$ & & \\
\hline \multirow[b]{2}{*}{ Gender } & Male & $8(30.8)$ & $7(26.9)$ & \multirow[b]{2}{*}{0.01} & \multirow[b]{2}{*}{$1.000^{\dagger}$} \\
\hline & Female & $6(23.1)$ & $5(19.2)$ & & \\
\hline Age (year) & $28-59$ & $46.43 \pm 8.25$ & $44.42 \pm 7.03$ & 0.66 & 0.514 \\
\hline \multirow{2}{*}{ Education } & $\leq$ Middle school & $2(7.7)$ & $4(15.4)$ & \multirow{2}{*}{2.06} & \multirow{2}{*}{0.725} \\
\hline & $\geq$ High school & $12(46.1)$ & $8(30.8)$ & & \\
\hline \multirow{2}{*}{ Marital status } & Single & $11(42.3)$ & $10(38.5)$ & \multirow[b]{2}{*}{0.90} & \multirow{2}{*}{0.638} \\
\hline & Married & $3(11.5)$ & $2(7.7)$ & & \\
\hline \multirow{2}{*}{ Religion } & Yes & $9(34.6)$ & $6(23.1)$ & \multirow{2}{*}{1.37} & \multirow{2}{*}{0.713} \\
\hline & No & $5(19.2)$ & $6(23.1)$ & & \\
\hline \multirow[b]{2}{*}{ Cohabitants } & Family & $12(46.1)$ & $9(34.7)$ & \multirow[b]{2}{*}{0.70} & \multirow[b]{2}{*}{0.952} \\
\hline & None & $2(7.7)$ & $3(11.5)$ & & \\
\hline \multirow{2}{*}{ Working status } & Employed & $3(11.5)$ & $1(3.9)$ & \multirow[b]{2}{*}{0.85} & \multirow{2}{*}{$0.598^{+}$} \\
\hline & Unemployed & $11(42.3)$ & $11(42.3)$ & & \\
\hline \multirow{2}{*}{ Monthly income } & None & $4(15.4)$ & $8(30.8)$ & \multirow{2}{*}{4.13} & \multirow{2}{*}{0.127} \\
\hline & Less than 850 USD & $10(38.4)$ & $4(15.4)$ & & \\
\hline \multirow{3}{*}{$\begin{array}{l}\text { Disease duration } \\
\text { (years) }\end{array}$} & $\leq 5$ & $1(3.8)$ & $2(7.6)$ & \multirow{3}{*}{23.32} & \multirow{3}{*}{0.224} \\
\hline & $6 \sim 9$ & $2(7.6)$ & $1(3.8)$ & & \\
\hline & $\geq 10$ & $11(42.4)$ & $9(34.8)$ & & \\
\hline \multirow{4}{*}{$\begin{array}{l}\text { Number of psychiatric } \\
\text { hospitalizations }\end{array}$} & No & $1(3.8)$ & $2(7.7)$ & \multirow{4}{*}{2.39} & \\
\hline & $1-2$ & $5(19.2)$ & $5(19.2)$ & & 0.792 \\
\hline & $\leq 3$ & $8(30.9)$ & $5(19.2)$ & & \\
\hline & $\leq 20$ & $2(7.6)$ & $4(15.2)$ & & \\
\hline Age at first onset & $21-29$ & $7(26.8)$ & $2(7.6)$ & 17.28 & 0.504 \\
\hline & $30-39$ & $5(19.0)$ & $6(23.8)$ & & \\
\hline Presence of & Yes & $9(34.6)$ & $8(30.8)$ & & \\
\hline support groups & No & $5(19.2)$ & $4(15.4)$ & 0.02 & $1.000^{\dagger}$ \\
\hline Perceiv & stress & $30.71(6.56)$ & $34.67(4.23)$ & -1.79 & 0.086 \\
\hline & & $26.82(16.70)$ & $29.34(15.43)$ & -0.40 & 0.695 \\
\hline Positi & ffect & $22.14(5.63)$ & $21.00(4.80)$ & 0.56 & 0.582 \\
\hline Negati & affect & $30.36(6.54)$ & $34.33(4.52)$ & -1.77 & 0.089 \\
\hline Subjective & ellbeing & $70.64(17.43)$ & $59.00(9.69)$ & 2.05 & 0.051 \\
\hline
\end{tabular}

$\mathrm{HRV}=$ heart rate variability; Exp. = experimental group; Cont. = control group; ${ }^{\dagger}$ Fisher's exact test; $\mathrm{M} \pm \mathrm{SD}=$ mean \pm standard deviation.

\subsection{Hypothesis Testing}

Hypothesis 1 ("Compared to the control group, the MBSR group will display a greater decrease in perceived stress."): Analyses revealed a significant group $\times$ time interaction $\left(\mathrm{F}(1.26,30.26)=3.95, p=0.034, \eta^{2}=0.256\right)$. Subsequent analyses showed a significant difference between groups at post-test $(\mathrm{t}(25)=-2.63, p=0.015)$ and follow-up $(\mathrm{t}(25)=-2.87$, $p=0.008$ ), such that the MBSR group scored lower on perceived stress relative to the control group (Figure 2a). 


\section{Perceived Stress}

$\multimap-$ experimental group $\quad-\leftarrow-$ control group

40

35

30

25

20

15

5

0

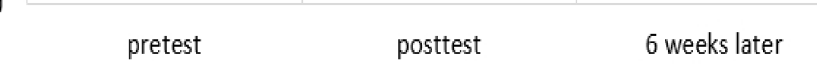

(a) Perceived stress

\section{Positive Affect}
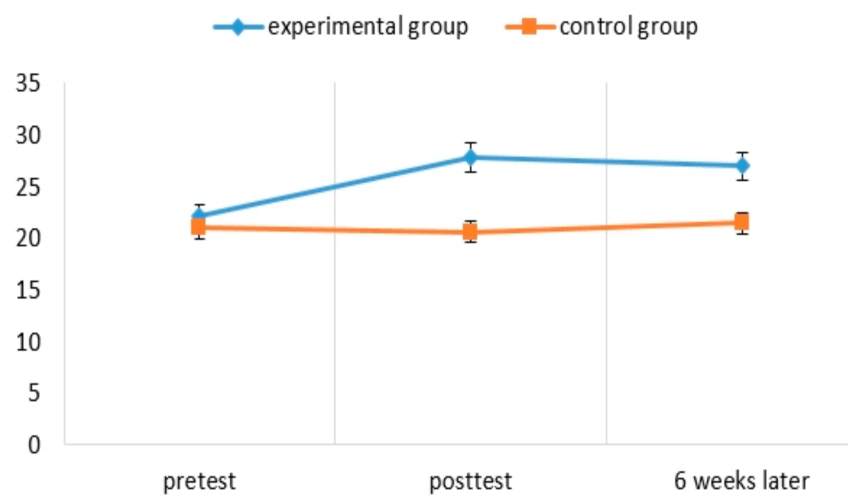

(c) Positive affect

\section{HRV}
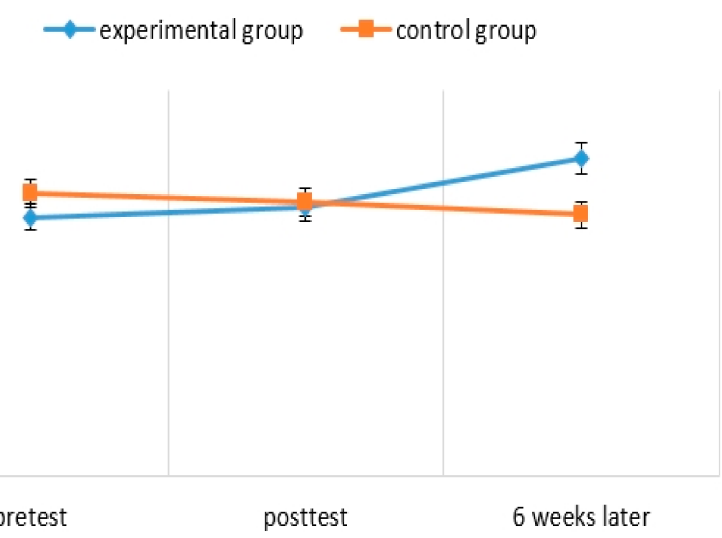

(b) HRV

\section{Negative Affect}
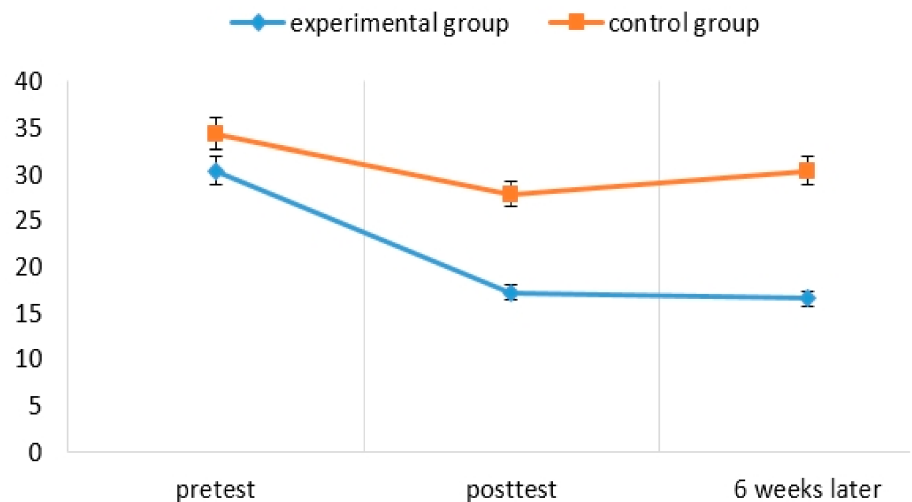

(d) Negative affect

\section{Subjective Well-being}

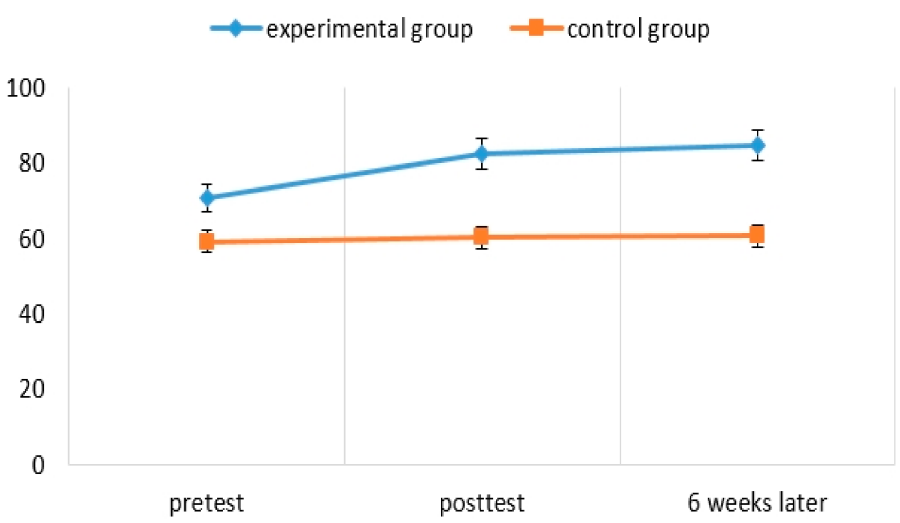

(e) Subjective well-being

Figure 2. Hypothesis testing: (a) perceived stress; (b) HRV; (c) positive affect; (d) negative affect; (e) subjective wellbeing.

Hypothesis 2 ("Compared to the control group, the MBSR group will display a greater increase in heart rate variability"): Analyses revealed a significant group $\times$ time interaction $\left(\mathrm{F}(1.57,37.61)=3.66, p=0.042, \eta^{2}=0.241\right)$. Subsequent analyses showed a non-significant difference between groups at post-test $(\mathrm{t}(25)=0.40, p=0.691)$ and follow-up $(\mathrm{t}(25)=2.00$, $p=0.057)$, such that the MBSR group scored higher on HRV relative to the control group (Figure 2b). 
Hypothesis 3 ("Compared to the control group, the MBSR group will display a greater increase in positive affect"): Analyses revealed no group $\times$ time interaction $(\mathrm{F}(1.17,28.11)=2.47$, $\left.p=0.107, \eta^{2}=0.177\right)$. Although a significant effect for group was observed $(\mathrm{F}(1,24)=4.67$, $\left.p=0.045, \eta^{2}=0.187\right)$, change over time was not statistically significant $(\mathrm{F}(1.17,28.11)=0.346$, $p=0.346, \eta^{2}=0.088$ ) (Figure $2 \mathrm{c}$ ).

Hypothesis 4 ("Compared to the control group, the MBSR group will display a greater decrease in negative affect"): Analyses revealed a significant group $\times$ time interaction $\left(\mathrm{F}(2,48)=4.55, p=0.022, \eta^{2}=0.283\right)$. Subsequent analyses showed a nonsignificant difference between groups at post-test $(t(25)=-1.87, p=0.074)$ and a significant difference at follow-up $(\mathrm{t}(25)=-0.302, p=0.006)$, such that the MBSR group scored lower on negative affect relative to the control group (Figure $2 \mathrm{~d}$ ).

Hypothesis 5 ("Compared to the control group, the MBSR group will display a greater increase in subjective well-being."): Analyses revealed no group $\times$ time interaction $\left(\mathrm{F}(1.33,31.88)=1.69, p=0.207, \eta^{2}=0.128\right)$. Although a significant effect for group was observed $\left(\mathrm{F}(1,24)=12.21, p=0.002, \eta^{2}=0.337\right)$, change over time was not statistically significant $\left(\mathrm{F}(1.33,31.88)=2.78, p=0.083, \eta^{2}=0.194\right)$ (Figure 2e). Appendix A Table A1 presents details on differences in dependent variables between groups over time.

\section{Discussion}

The experimental group, which received the MBSR program, showed decreases in perceived stress and negative affect, as well as significant improvements in HRV, compared to the control group. However, there were no improvements in positive affect or subjective wellbeing. These results are consistent with those of previous studies $[43,44]$ that analyzed the effects of MBSR programs, and they indicate that the MBSR program had effects on perceived stress and HRV.

These results suggest that the eight-session MBSR program effectively reduced stress in patients with chronic schizophrenia residing in the local community. Although the standard MBSR sessions are commonly $150 \mathrm{~min}$ each, the currently program was modified, offering $60 \mathrm{~min}$ sessions due to the nature of the target sample. Indeed, persons with schizophrenia are more likely to have difficulty in concentrating [45], and the $60 \mathrm{~min}$ sessions were aligned with the programs offered at the community mental health centers. Despite the short duration of the sessions, this program was effective in reducing stress.

After conducting the program, HRV, which reflects a physiological response to stress, showed a significant increase in the experimental group compared to the control group. This result is consistent with that of a previous study [46,47], which observed changes in HRV after applying the breathing meditation method to healthy adults. These results can be attributed to activation of the parasympathetic nervous system and hypoactivation of the sympathetic nervous system through the MBSR program using meditation, which provides training in meditation with an attitude of nonjudgmental acceptance, along with awareness and intention. The results suggest that this program can be used as an effective method for improving adaptability to the external environment [47]. In addition, HRV reflects the activity of the vagus nerve, which is a major component of the parasympathetic nervous system. Therefore, a higher HRV implies mental and physical stability [48], and meditation leads to changes in the activation of the vagus nerve [49], affecting the ability to concentrate on sensory input and facilitating relaxation of mental and physiological tension. However, although a significant interaction was observed for HRV, post hoc analyses failed to reach statistical significance. As such, these results must be interpreted with caution.

There was no statistically significant difference in positive affect between the experimental and control groups. This result is inconsistent with that of a previous study [50] that observed a change in positive affect after patients with schizophrenia participated in meditation. An explanation for this inconsistency is that the meditation program provided for people with schizophrenia in the previous study [50] mainly consisted of loving-kindness meditation, which focuses on fostering feelings of being happy, cozy, and comfortable. Instead, the MBSR program applied in this study included various elements, such as breath- 
ing meditation, body scanning, yoga meditation, walking meditation, eating meditation, and loving-kindness meditation. Another possible reason is that the MBSR training in this study may have helped enhance awareness by connecting body and mind [23] rather than directly leading to changes in positive emotions such as happiness. Thus, this inconsistency could be attributed to negative symptoms such as anhedonia, apathy, and flat affect in people with chronic schizophrenia, which would offset any meaningful increase in positive affect. Therefore, additional research is required to investigate the effect of MBSR programs on positive affect.

Negative affect was reduced in the experimental group compared to the control group. This result is similar to those of previous studies that observed changes in negative affect in adults through meditation [51,52]. In addition, the results of this study are aligned with previous meta-analyses $[24,25]$, which found that MBIs were effective for the negative symptoms of people with schizophrenia. An explanation for this result could be that the MBSR program allowed participants to choose an adaptive direction of cognition, departing from dysfunctional aspects through training to become aware of their thoughts and emotions [53]. In the post hoc analysis of negative affect, there was a significant difference between the experimental group and the control group at 6 weeks following the intervention, but not immediately after the intervention. A reason for this delayed effect might be that the researcher encouraged participants to engage in home practice and to continue mindfulness meditation by visiting the community mental health center once a week or having a phone consultation after the 8 week program. Furthermore, the delayed effect on negative affect in this study is consistent with a previous study [52] showing that perceived stress and negative affect gradually decreased in a linear fashion over time with sustained MBSR practice.

The MBSR program conducted in this study exhibited no effect on the subjective wellbeing of people with schizophrenia. In this aspect, the results of this study are inconsistent with those of a previous study [54] that observed a change in wellbeing after providing a meditation program for adults in the local community, as well as another study that applied an MBSR program to people with social anxiety disorder [55] that showed a difference. This inconsistency could be attributed to the distinct characteristics among participants, since the present study targeted patients with schizophrenia. The null association for subjective wellbeing may be attribute to baseline function. More specifically, the experimental group was marginally better off than the control group and may have experienced a ceiling effect, preventing significant change over time for this particular sample. Moreover, during the course of the study, the participants commented, "Mindfulness meditation gave me comfort," "I felt lighthearted and relaxed," "I felt agitated at the beginning, but, after patiently sticking with meditation, I felt at ease," and "I became warmhearted and comfortable," which all suggest that the participants' wellbeing subjectively improved. Follow-up research is, therefore, required to investigate the effect of the MBSR program on subjective wellbeing in people with schizophrenia.

This study had some limitations. First, it is difficult to generalize the results of this study to all people with schizophrenia since participants were allocated to the experimental group and the control group by convenience sampling. Future research using randomized assignment is necessary. The participants of this study were limited to those who were assessed as having insight into their condition based on a score of 9 or less according to the SUMD [30], and those with good function, who were determined to have symptoms of moderate severity, with a score of 31 or more and less than 41 on the Brief Psychiatric Rating Scale (BPRS). Second, the participants who had relatively low levels of self-expression experienced difficulties in actively participating in the group because they exchanged relatively few verbal expressions while sharing meditation experiences after meditation practice. Thus, future research requires a strategy to better motivate self-expression by adding words or pictures as examples to the workbook to promote smooth self-expression. Third, the program was conducted in the program room due to the conditions of the center; 
this space was somewhat narrow, and the floor was uncomfortable for sitting. It would be ideal to create a more suitable environment for practicing yoga and walking meditation.

To this end, the current study showed that MBSR may minimize stress and negative affect among South Korean outpatients with schizophrenia. The results of this study are important as they dispute the misconception that mindfulness meditation is not helpful for people with schizophrenia. In addition, a meaningful aspect of the MBSR program is that it can be applied as an intervention across community mental health centers. Further, once patients learn the techniques, they are able to continue their practice.

\section{Conclusions}

The MBSR program decreased perceived stress and negative affect and increased heart rate variability in people with schizophrenia. This study provides guidance for further programs based on mindfulness. Furthermore, in light of these results, incorporating MBSR programs into routine psychosocial interventions at community mental health centers may contribute to improvements in the treatment process of people with schizophrenia.

Author Contributions: Conceptualization, A.S.K. and M.H.J.; data curation, A.S.K.; formal analysis, M.H.J. and M.J.S.; investigation, A.S.K.; methodology, A.S.K. and M.H.J.; resources, M.J.S.; supervision, M.H.J.; validation, M.H.J. and M.J.S.; visualization, M.J.S.; writing—original draft, A.S.K.; writing—review and editing, M.H.J. and M.J.S. All authors have read and agreed to the published version of the manuscript.

Funding: This research received no external funding.

Institutional Review Board Statement: The study was conducted in accordance with the Declaration of Helsinki and approved by the Institutional Review Board of Kyung Hee University (protocol code: KHSIRB-18-041(NA)).

Informed Consent Statement: Informed consent was obtained from all subjects involved in the study.

Data Availability Statement: The data presented in this study are available from the authors upon reasonable request.

Acknowledgments: The authors gratefully acknowledge the cooperation of all the participants in this study.

Conflicts of Interest: The authors declare no conflict of interest.

\section{Appendix A}

Table A1. Differences in dependent variables between groups over time.

\begin{tabular}{|c|c|c|c|c|c|c|c|c|c|c|c|c|c|}
\hline \multirow{2}{*}{ Variable } & \multirow{2}{*}{ Group } & \multirow{2}{*}{$\begin{array}{l}\text { Pre-Test } \\
\mathbf{M} \pm \mathbf{S D}\end{array}$} & \multirow{2}{*}{$\begin{array}{c}\begin{array}{c}\text { Posttest } 1 \\
\text { (Post } \\
8 \text { Weeks) }\end{array} \\
\mathrm{M} \pm \mathrm{SD}\end{array}$} & \multirow{2}{*}{$\begin{array}{c}\begin{array}{c}\text { Posttest 2 } \\
\text { (Post } \\
14 \text { Weeks) }\end{array} \\
\mathrm{M} \pm \mathrm{SD}\end{array}$} & \multirow{2}{*}{ Source } & \multirow{2}{*}{$F(d f 1, d f 2)$} & \multirow{2}{*}{$p$} & \multicolumn{3}{|c|}{ Differences (Post 1-Pre) } & \multicolumn{3}{|c|}{ Differences (Post 2-Pre) } \\
\hline & & & & & & & & $\mathbf{M} \pm \mathbf{S D}$ & $t(d f)$ & $p$ & $\mathbf{M} \pm \mathbf{S D}$ & $t(d f)$ & $p$ \\
\hline \multirow{3}{*}{$\begin{array}{l}\text { Perceived } \\
\text { Stress }\end{array}$} & Exp. & $30.71 \pm 6.56$ & $23.00 \pm 5.17$ & $22.36 \pm 4.60$ & G & $17.69(1,24)$ & $<0.001$ & $-7.71 \pm 5.89$ & $-2.63(25)$ & 0.015 & $-8.35 \pm 5.60$ & $-2.87(25)$ & 0.008 \\
\hline & Cont. & $34.67 \pm 4.23$ & $32.83 \pm 5.84$ & $33.00 \pm 7.23$ & $\mathrm{~T}$ & $\begin{array}{c}9.17 \\
(1.26,30.26)\end{array}$ & 0.001 & $-1.84 \pm 5.46$ & & & $-1.67 \pm 6.29$ & & \\
\hline & & & & & $\mathrm{G} \times \mathrm{T}$ & $\begin{array}{c}3.95 \\
(1.26,30.26)\end{array}$ & 0.034 & & & & & & \\
\hline \multirow{3}{*}{ HRV } & Exp. & $26.82 \pm 16.70$ & $27.90 \pm 12.69$ & $32.98 \pm 14.43$ & G & $0.48(1,24)$ & 0.848 & $1.08 \pm 16.01$ & $0.40(25)$ & 0.691 & $6.16 \pm 12.39$ & $2.00(25)$ & 0.057 \\
\hline & Cont. & $29.34 \pm 15.43$ & $28.36 \pm 12.05$ & $27.13 \pm 12.00$ & $\mathrm{~T}$ & $\begin{array}{c}1.08 \\
(1.57,37.61)\end{array}$ & 0.356 & $-0.98 \pm 8.42$ & & & $-2.21 \pm 8.04$ & & \\
\hline & & & & & $\mathrm{G} \times \mathrm{T}$ & $\begin{array}{c}3.66 \\
(1.57,37.61)\end{array}$ & 0.042 & & & & & & \\
\hline \multirow{3}{*}{$\begin{array}{l}\text { Positive } \\
\text { Affect }\end{array}$} & Exp. & $22.14 \pm 5.63$ & $27.79 \pm 9.42$ & $27.00 \pm 8.81$ & G & $4.67(1,24)$ & 0.045 & $5.65 \pm 7.50$ & $1.76(25)$ & 0.090 & $4.86 \pm 7.56$ & $1.19(25)$ & 0.246 \\
\hline & Cont. & $21.00 \pm 4.80$ & $20.58 \pm 8.96$ & $21.41 \pm 10.19$ & $\mathrm{~T}$ & $\begin{array}{c}1.11 \\
(1.17,28.11)\end{array}$ & 0.346 & $-0.42 \pm 10.00$ & & & $0.41 \pm 11.37$ & & \\
\hline & & & & & $\mathrm{G} \times \mathrm{T}$ & $\begin{array}{c}2.47 \\
(1.17,28.11)\end{array}$ & 0.107 & & & & & & \\
\hline \multirow{2}{*}{$\begin{array}{l}\text { Negative } \\
\text { Affect }\end{array}$} & Exp. & $30.36 \pm 6.54$ & $17.21 \pm 5.26$ & $\begin{array}{l}16.50 \pm 4.45 \\
30.33+8.64\end{array}$ & G & $2.91(1,24)$ & 0.101 & $-13.15 \pm 9.26$ & $-1.87(25)$ & 0.074 & $-13.86 \pm 7.60$ & $-3.02(25)$ & 0.006 \\
\hline & Cont. & & & $30.33 \pm 8.64$ & $\mathrm{G} \times \mathrm{T}$ & $\begin{array}{c}24.35(2,48) \\
4.55(2,48)\end{array}$ & $\begin{array}{l}<0.001 \\
0.022\end{array}$ & $-6.50 \pm 8.77$ & & & & & \\
\hline \multirow{3}{*}{$\begin{array}{l}\text { Subjective } \\
\text { Well-being }\end{array}$} & Exp. & $70.64 \pm 17.43$ & $82.35 \pm 16.82$ & $84.71 \pm 15.24$ & G & $12.21(1,24)$ & 0.002 & $11.71 \pm 17.83$ & $1.39(25)$ & 0.177 & $14.07 \pm 16.56$ & $1.81(25)$ & 0.083 \\
\hline & Cont. & $59.00 \pm 9.69$ & $60.25 \pm 19.97$ & $60.66 \pm 19.15$ & $\mathrm{~T}$ & $\begin{array}{c}2.78 \\
(1.33,31.88)\end{array}$ & 0.083 & $1.25 \pm 20.54$ & & & $1.67 \pm 18.37$ & & \\
\hline & & & & & $\mathrm{G} \times \mathrm{T}$ & $\begin{array}{c}1.69 \\
(1.33,31.88)\end{array}$ & 0.207 & & & & & & \\
\hline
\end{tabular}

Cont. = control group; Exp. = experimental group; $\mathrm{M}=$ mean; $\mathrm{SD}=$ standard deviation.; $\mathrm{G}=$ group; $\mathrm{T}=$ time; $\mathrm{G} \times \mathrm{T}=$ group $\times$ time; $\mathrm{df}=$ degree of freedom . 


\section{References}

1. Moreno-Küstner, B.; Martin, C.; Pastor, L. Prevalence of psychotic disorders and its association with methodological issues. A systematic review and meta-analyses. PLoS ONE 2018, 13, e0195687. [CrossRef]

2. Kim, S.W. Psychosocial intervention for patients with schizophrenia. J. Korean Neuropsychiatr. Assoc. 2018, 57, 235-243. [CrossRef]

3. Kumar, S.; Mohanty, S. Factors associated with self-esteem in patients with chronic schizophrenia. SIS J. Proj. Psychol. Ment. Health 2016, 23, 56-60.

4. Lee, H.Y.; Ham, B.J. Stress and mental illness. J. Korean Med. Assoc. 2013, 56, 471-477. [CrossRef]

5. OECD [Organization for Economic Cooperation and Development]. Health Statistics; OECD: Paris, France, 2015.

6. Mitchell, A.J.; Vancampfort, D.; Sweers, K.; van Winkel, R.; Yu, W.; De Hert, M. Prevalence of metabolic syndrome and metabolic abnormalities in schizophrenia and related disorders-A systematic review and meta-analysis. Schizophr. Bull. 2011, 39, 306-331. [CrossRef]

7. Lee, J.-S.; Yoon, B.-H.; Song, J.-H.; Hea, Y.-H. The Effect of Weight Reduction on the Obesity-Related Quality of Life, Physical and Emotional Well-Being in Obese Schizophrenic Inpatients. Korean J. Psychopharmacol. 2012, 23, 190-199.

8. Kim, M.Y.; Jun, S.S. Development and Effects of a Cognitive-behavioral Therapy Based Program in Reducing Internalized Stigma in Patients with Schizophrenia. J. Korean Acad. Nurs. 2016, 46, 349-363. [CrossRef]

9. Schultz, S.H.; North, S.W.; Shields, C.G. Schizophrenia: A review. Am. Fam. Physician 2007, 75, 1821-1829. [PubMed]

10. Wang, L.Q.; Chien, W.T.; Yip, L.K.; Karatzias, T. A randomized controlled trial of a mindfulness-based intervention program for people with schizophrenia: 6-month follow-up. Neuropsychiatr. Dis. Treat. 2016, 12, 3097. [CrossRef] [PubMed]

11. Chadwick, P.; Taylor, K.N.; Abba, N. Mindfulness groups for people with psychosis. Behav. Cogn. Psychother. 2005, 33, 351-359. [CrossRef]

12. van der Valk, R.; van de Waerdt, S.; Meijer, C.J.; van den Hout, I.; de Haan, L. Feasibility of mindfulness-based therapy in patients recovering from a first psychotic episode: A pilot study. Early Interv. Psychiatry 2013, 7, 64-70. [CrossRef]

13. Wahbeh, H.; Nelson, M. iRest meditation for older adults with depression symptoms: A pilot study. Int. J. Yoga Ther. 2019, 29, 9-17. [CrossRef] [PubMed]

14. Hofmann, S.G.; Sawyer, A.T.; Witt, A.A.; Oh, D. The effect of mindfulness-based therapy on anxiety and depression: A metaanalytic review. J. Consult. Clin. Psychol. 2010, 78, 169-183. [CrossRef]

15. Henderson, V.P.; Clemow, L.; Massion, A.O.; Hurley, T.G.; Druker, S.; Hébert, J.R. The effects of mindfulness-based stress reduction on psychosocial outcomes and quality of life in early-stage breast cancer patients: A randomized trial. Breast Cancer Res. Treat. 2012, 131, 99-109. [CrossRef] [PubMed]

16. Shin, K.C.; Park, E.J. PT746. The Effect of Mindfulness Meditation Programs on Perceived Stress and Quality of Life of Mental Health Professionals: A Pilot Study. Int. J. Neuropsychopharmacol. 2016, 19 (Suppl. S1), 71. [CrossRef]

17. Khoury, B.; Lecomte, T.; Fortin, G.; Masse, M.; Therien, P.; Bouchard, V.; Chapleau, M.-A.; Paquin, K.; Hofmann, S.G. Mindfulnessbased therapy: A comprehensive meta-analysis. Clin. Psychol. Rev. 2013, 33, 763-771. [CrossRef] [PubMed]

18. Eberth, J.; Sedlmeier, P. The effects of mindfulness meditation: A meta-analysis. Mindfulness 2012, 3, 174-189. [CrossRef]

19. Shawyer, F.; Farhall, J.; Mackinnon, A.; Trauer, T.; Sims, E.; Ratcliff, K.; Larner, C.; Thomas, N.; Castle, D.; Mullen, P.; et al. A randomised controlled trial of acceptance-based cognitive behavioural therapy for command hallucinations in psychotic disorders. Behav. Res. Ther. 2012, 50, 110-121. [CrossRef] [PubMed]

20. Tang, Y.Y.; Hölzel, B.K.; Posner, M.I. The neuroscience of mindfulness meditation. Nat. Rev. Neurosci. 2015, 16, 213-225. [CrossRef] [PubMed]

21. Baer, R.A. (Ed.) Mindfulness-Based Treatment Approaches: Clinician's Guide to Evidence Base and Applications; Elsevier: Amsterdam, The Netherlands, 2015.

22. Santorelli, S.; Kabat-Zinn, J. (Eds.) Mindfulness-Based Stress Reduction Professional Training: Scientific Papers from the Stress Reduction Clinic and the Center for Mindfulness in Medicine, Health Care, and Society 2001-1982; Center for Mindfulness in Medicine, Health Care, and Society: Worcester, MA, USA, 2014.

23. Kabat-Zinn, J. Mindfulness-based interventions in context: Past, present, and future. Clin. Psychol. Sci. Pract. 2003, 10, 144-156. [CrossRef]

24. Hodann-Caudevilla, R.M.; Díaz-Silveira, C.; Burgos-Julián, F.A.; Santed, M.A. Mindfulness-based interventions for people with schizophrenia: A systematic review and meta-analysis. Int. J. Environ. Res. Public Health 2020, 17, 4690. [CrossRef]

25. Liu, Y.-C.; Li, I.-L.; Hsiao, F.-H. Effectiveness of mindfulness-based intervention on psychotic symptoms for patients with schizophrenia: A meta-analysis of randomized controlled trials. J. Adv. Nurs. 2021, 77, 2565-2580. [CrossRef]

26. Goldberg, S.B.; Tucker, R.P.; Greene, P.A.; Davidson, R.J.; Wampold, B.E.; Kearney, D.J.; Simpson, T.L. Mindfulness-based interventions for psychiatric disorders: A systematic review and meta-analysis. Clin. Psychol. Rev. 2017, 59, 52-60. [CrossRef]

27. Kuijpers, H.J.; Van der Heijden, F.; Tuinier, S.; Verhoeven, W.M.A. Meditation-induced psychosis. Psychopathology 2007, 40, 461-464. [CrossRef]

28. Jung, C.Y.; Kim, S.H.; Lee, W.K.; Kim, W.Y. The effects of meditation program combining mindfulness and compassion meditation on emotional state of chronic inpatients with schizophrenia: Pilot study. J. Korean Assoc. Soc. Psychiatry 2011, 16, 66-73.

29. Kim, S.H.; Lee, Y.K. The effects of mindfulness based group intervention on negative symptom, emotional state, and ward behavior with chronic schizophrenia: A preliminary study. Korean J. Schizophr. Res. 2011, 14, 27-33. 
30. Song, J.Y.; Kim, K.T.; Lee, S.K.; Kim, Y.H.; Noh, J.H.; Kim, J.W.; Chang, W.I.; Bahn, G.H.; Kang, W.S. Reliability and validity of the Korean version of the scale to assessment unawareness of mental disorder (SUMD-K). J. Korean Neuropsychiatr. Assoc. 2006, 45, 307-315.

31. Faul, F.; Erdfelder, E.; Buchner, A.; Lang, A.G. Statistical power analyses using G*Power 3.1: Tests for correlation and regression analyses. Behav. Res. Methods 2009, 41, 1149-1160. [CrossRef] [PubMed]

32. la Cour, P.; Petersen, M. Effects of mindfulness meditation on chronic pain: A randomized controlled trial. Pain Med. 2015, 16, 641-652. [CrossRef]

33. Son, M.A.; Lee, Y.M.; Jung, K.A. The effects of a combined exercise program on obesity and metabolic syndrome factors for chronic psychiatric inpatients. J. Korean Biol. Nurs. Sci. 2014, 16, 105-112. [CrossRef]

34. Stahl, B.; Goldstein, E. A Mindfulness-Based Stress Reduction Workbook; New Harbinger Publications: Oakland, CA, USA, 2010.

35. Shapiro, S.L.; Schwartz, G.E.R. Intentional systemic mindfulness: An integrative model for self-regulation and health. Adv. Mind-Body Med. 2000, 16, 128-134. [PubMed]

36. Arch, J.J.; Ayers, C.R.; Baker, A.; Almklov, E.; Dean, D.J.; Craske, M.G. Randomized clinical trial of adapted mindfulness-based stress reduction versus group cognitive behavioral therapy for heterogeneous anxiety disorders. Behav. Res. Ther. 2013, 51, 185-196. [CrossRef]

37. Park, J.O.; Seo, Y.S. Validation of the perceived stress scale (PSS) on samples of Korean university students. Korean J. Psychol. Gen. 2010, 29, 611-629.

38. Cohen, F. Coping. Behavioral Health: A Handbook of Health Enhancement and Disease Prevention; Wiley: New York, NY, USA, 1984.

39. Lim, Y.J.; Yu, B.H.; Kim, D.K.; Kim, J.H. The positive and negative affect schedule: Psychometric properties of the Korean version. Psychiatry Investig. 2010, 7, 163-169. [CrossRef] [PubMed]

40. Watson, D.; Clark, L.A.; Tellegen, A. Development and validation of brief measures of positive and negative affect: The PANAS scales. J. Personal. Soc. Psychol. 1988, 54, 1063-1070. [CrossRef]

41. Kim, S.W.; Shin, I.S.; Kim, J.M.; Yoo, J.A.; Ahn, Y.M.; Kwon, J.S.; Yang, S.J.; Yoon, J.S. A validation study of the Korean version of the subjective well-being under neuroleptic treatment scale-short form. Korean J. Psychopharmacol. 2007, 18, 221-230.

42. Naber, D.; Moritz, S.; Lambert, M.; Rajonk, F.; Holzbach, R.; Mass, R.; Andresen, B.; Frank, P.; Rüdiger, H.; Reinhard, M.; et al. Improvement of schizophrenic patients' subjective well-being under atypical antipsychotic drugs. Schizophr. Res. 2001, 50, 79-88. [CrossRef]

43. Kolahkaj, B.; Zargar, F. Effect of mindfulness-based stress reduction on anxiety, depression and stress in women with multiple sclerosis. Nurs. Midwifery Stud. 2015, 4, e29655. [CrossRef] [PubMed]

44. Marzabadi, E.A.; Zadeh, S.M.H. The Effectiveness of Mindfulness Training in Improving the Quality of Life of the War Victims with Post Traumatic stress disorder (PTSD). Iran. J. Psychiatry 2014, 9, 228-236. Available online: http:/ / eprints.bmsu.ac.ir/id/ eprint/1753 (accessed on 10 July 2021).

45. Mihaljević-Peleš, A.; Bajs Janović, M.; Šagud, M.; Živković, M.; Janović, Š.; Jevtović, S. Cognitive deficit in schizophrenia: An overview. Psychiatr. Danub. 2019, 31, 139-142. [PubMed]

46. Krygier, J.R.; Heathers, J.A.; Shahrestani, S.; Abbott, M.; Gross, J.J.; Kemp, A.H. Mindfulness meditation, well-being, and heart rate variability: A preliminary investigation into the impact of intensive Vipassana meditation. Int. J. Psychophysiol. 2013, 89, 305-313. [CrossRef] [PubMed]

47. Fogarty, F.A.; Lu, L.M.; Sollers, J.J.; Krivoschekov, S.G.; Booth, R.J.; Consedine, N.S. Why it pays to be mindful: Trait mindfulness predicts physiological recovery from emotional stress and greater differentiation among negative emotions. Mindfulness 2015, 6, 175-185. [CrossRef]

48. Suh, J.W.; Hwang, E.Y.; Chung, S.Y.; Hang, W.W.; Kim, J.W. Effect of Meditation According to Emotional State and Meditation Subgroup Evaluated by HRV (Heart Rate Variability). J. Orient. Neuropsychiatry 2009, 20, 133-147.

49. Léonard, A.; Clément, S.; Kuo, C.D.; Manto, M.U. Changes in Heart Rate Variability During Heartfulness Meditation: A Power Spectral Analysis Including the Residual Spectrum. Front. Cardiovasc. Med. 2019, 6, 62. [CrossRef] [PubMed]

50. Johnson, D.P.; Penn, D.L.; Fredrickson, B.L.; Kring, A.M.; Meyer, P.S.; Catalino, L.I.; Brantley, M. A pilot study of loving-kindness meditation for the negative symptoms of schizophrenia. Schizophr. Res. 2011, 129, 137-140. [CrossRef]

51. Beblo, T.; Pelster, S.; Schilling, C.; Kleinke, K.; Iffland, B.; Driessen, M.; Fernando, S. Breath versus emotions: The impact of different foci of attention during mindfulness meditation on the experience of negative and positive emotions. Behav. Ther. 2018, 49, 702-714. [CrossRef]

52. Snippe, E.; Dziak, J.J.; Lanza, S.T.; Nyklíček, I.; Wichers, M. The shape of change in perceived stress, negative affect, and stress sensitivity during mindfulness-based stress reduction. Mindfulness 2017, 8, 728-736. [CrossRef]

53. Garland, E.; Gaylord, S.; Park, J. The role of mindfulness in positive reappraisal. Explore 2009, 5, 37-44. [CrossRef]

54. Szekeres, R.A.; Wertheim, E.H. Evaluation of Vipassana meditation course effects on subjective stress, well-being, self-kindness and mindfulness in a community sample: Post-course and 6-month outcomes. Stress Health 2015, 31, 373-381. [CrossRef]

55. Jazaieri, H.; Goldin, P.R.; Werner, K.; Ziv, M.; Gross, J.J. A randomized trial of MBSR versus aerobic exercise for social anxiety disorder. J. Clin. Psychol. 2012, 68, 715-731. [CrossRef] 